\title{
Low Temperature and Binding to Food Components Inhibit the Antibacterial Activity of Carvacrol against Listeria monocytogenes in Steak Tartare
}

\author{
EDWIN J. A. VELDHUIZEN, ${ }^{*} *$ T. OLAF CREUTZBERG, ${ }^{1}$ SARA A. BURT, ${ }^{2}$ AND HENK P. HAAGSMAN ${ }^{1}$ \\ ${ }^{1}$ Department of Infectious Diseases and Immunology and ${ }^{2}$ Institute for Risk Assessment Sciences, Division Veterinary Public Health; Faculty of \\ Veterinary Medicine, Utrecht University, Utrecht, The Netherlands
}

MS 07-056: Received 1 February 2007/Accepted 16 April 2007

\begin{abstract}
Carvacrol is a major component of thyme and oregano essential oils and has potential uses as a food preservative. The effect of carvacrol on the growth of Listeria monocytogenes was investigated in vitro and in steak tartare. Carvacrol had strong antilisterial activity in growth medium $(\mathrm{MIC}=1.6 \mathrm{mM})$, but no effect was observed when carvacrol was tested in steak tartare. There were two reasons for this reduced activity: the antilisterial activity of carvacrol was strongly reduced at lower temperatures $\left(10\right.$ versus $\left.30^{\circ} \mathrm{C}\right)$, and the presence of food components interfered with the activity of carvacrol. Both bovine serum albumin and egg yolk inhibited carvacrol activity at $>0.2 \%(\mathrm{wt} / \mathrm{vol})$ in growth medium. For the first time, carvacrol was found to bind to albumin, suggesting that the reduced antilisterial activity of carvacrol in foods such as dairy products and uncooked meats is the result of fewer free unbound carvacrol molecules available to interact with bacteria.
\end{abstract}

Listeriosis is a foodborne disease caused by the bacterium Listeria monocytogenes (LM). This pathogen is a psychrotrophic gram-positive organism and is very hardy because of its ability to grow at low temperatures and in the presence of high salt and acid concentrations or low iron concentrations. LM has been isolated from a variety of food products such as uncooked meats, eggs, seafood, and dairy products (8). The consumption of food contaminated with LM can constitute a serious health risk to humans. Symptoms of listeriosis include abortion, neonatal death, septicemia, and meningitis (8). Groups at risk are the elderly, newborn infants, pregnant women, fetuses, and immunocompromised individuals.

In recent years, food safety awareness has grown tremendously, especially concerning the presence of foodborne microorganisms. There also is a growing demand for the use of natural rather than synthetic preservatives. Essential oils (EOs) and their components have potential for use as natural food preservatives (3). One of the EO components with the highest in vitro antibacterial activity is carvacrol, which is present in high concentrations in thyme and oregano oil $(1,29)$. This phenolic compound also has antifungal, insecticidal, antitoxigenic, and antiparasitic activities $(6,19,24,30,31)$. The main target of carvacrol seems to be the bacterial membrane, although interaction with bacterial DNA also has been suggested (2). Other EO components with similar activity, such as thymol or eugenol, share the presence of a hydroxyl group in common with carvacrol. This common presence of the hydroxyl group could indicate the necessity of this group for anti-

\footnotetext{
* Author for correspondence. Tel: +31 30 2535361; Fax: +31 30
} 2532365; E-mail: e.veldhuizen@vet.uu.nl. microbial activity or could be related to solubility characteristics, because most EO components are immiscible in aqueous solutions (32).

Despite the high antimicrobial activity of carvacrol (and EOs) under laboratory conditions, the preservative activity of this compound seems to be hampered in food matrices. In several reports, high concentrations of EO (components) were needed to reduce growth of LM in cheese and minced meat (33), chicken (15), ham (12), and liver sausage (23). A similar need for higher concentrations of EOs has been reported for other food products such as fish, dairy products, and vegetables, although a few exceptions exist (3). The higher concentrations needed often cannot be used in practice because of the aroma connected to these EOs. It is generally believed that the higher fat and protein contents of food compared with growth medium is the major cause of this higher microbial resistance to EOs. One hypothesis is that the food product provides more nutrients to bacteria, thereby enabling them to repair damaged cells more quickly (12). Another suggestion is that EO components can dissolve in the fat-lipid phase of the food, which would make these components less available to act on bacteria present in the water phase of these foods $(7,20)$.

In this study, the effect of carvacrol on LM under laboratory conditions and in steak tartare was investigated. Steak tartare, also known as Filet Américain in Belgium and The Netherlands, is a ready-to-eat raw meat product that consists of $70 \%$ ground beef and 30\% mayonnaisebased sauce. The activity of carvacrol was strongly inhibited in steak tartare. The temperature dependence of the antibactericidal activity of carvacrol against LM also was determined. Two components of steak tartare inhibited the antimicrobial effect of carvacrol, and binding of carvacrol 
to the food components is the most likely cause of this inhibiting effect.

\section{MATERIALS AND METHODS}

Preparation of cultures. The LM used was a Dutch field isolate obtained from cheese. Overnight cultures of LM were freshly prepared for every experiment by cultivation from frozen stock at $30^{\circ} \mathrm{C}$ for $16 \mathrm{~h}$ in tryptone soya broth (TSB). Before use in the antimicrobial assays, the optical density (OD) of the suspension was measured with a Ultrospec III spectrophotometer (Pharmacia Biotech, Roosendaal, the Netherlands) at $620 \mathrm{~nm}$, and the suspensions were diluted in TSB to the appropriate bacterial density needed in the experiments.

Growth curves. Growth curves of bacteria in TSB containing carvacrol were determined from data obtained with a Bioscreen C OD reader (Oy Growth Curves, AB Ltd., Helsinki, Finland) and software version 2.28. A stock preparation of $1 \mathrm{M}$ carvacrol was made up in $96 \%$ ethanol and diluted in TSB to the appropriate concentration. Final ethanol concentrations never exceeded $2 \%(\mathrm{vol} / \mathrm{vol})$ to eliminate the possibility of an antibacterial effect from the ethanol (which was observed when ethanol concentrations were $4 \%$ or higher in other experiments). From the 1 $\mathrm{M}$ stock solution in ethanol, a $5 \mathrm{mM}$ working solution was prepared in TSB, which was shaken vigorously for $2 \mathrm{~h}$ at $37^{\circ} \mathrm{C}$ to completely dissolve the carvacrol in the growth medium. In a typical experiment, $100-\mu 1$ aliquots of LM suspension containing $2 \times 10^{6} \mathrm{CFU} / \mathrm{ml}$ were added to $100 \mu \mathrm{l}$ of carvacrol in TSB. Bacterial densities used in the experiments were checked by plating on tryptone soya agar (TSA) plates for $24 \mathrm{~h}$ at $30^{\circ} \mathrm{C}$. All wells were incubated for $18 \mathrm{~h}$ at $37^{\circ} \mathrm{C}$ with continuous shaking. OD measurements (broad filter of 420 to $580 \mathrm{~nm}$ ) were obtained automatically every $40 \mathrm{~min}$. Each experiment was carried out twice with at least three replicates each time. A positive growth control containing no carvacrol was included on every occasion, and negative controls containing no bacteria were included in each experiment. The MIC was defined as the lowest concentration at which no increase in OD was observed after $18 \mathrm{~h}$.

Bactericidal activity of carvacrol. The bactericidal activity of carvacrol was tested in triplicate at 10,20 , and $30^{\circ} \mathrm{C}$. An overnight LM culture was diluted to $2 \times 10^{6} \mathrm{CFU} / \mathrm{ml}$ in $1 \mathrm{ml}$ of TSB of the appropriate temperature, and $1 \mathrm{ml}$ carvacrol in TSB was added to final concentrations of $0,1.25$, and $2.5 \mathrm{mM}$. Samples were then incubated at 10,20 , and $30^{\circ} \mathrm{C}$. Samples were removed after 3, 24, 48, 72, and $96 \mathrm{~h}$, serially diluted in physiological salt solution $(154 \mathrm{mM} \mathrm{NaCl})$, and plated on TSA for enumeration of colonies.

Effect of carvacrol on LM growth in steak tartare. Steak tartare was made by hand as follows. Seventy grams of ground beef was bought from a local supermarket and mixed with $30 \mathrm{~g}$ of Filet Américain sauce (Picol Americain, Verstegen BV, the Netherlands). This mixture was then spiked with LM at $10^{7}$ $\mathrm{CFU} / \mathrm{g}$ of steak tartare and divided into two samples. Carvacrol at $5 \mathrm{mmole} / \mathrm{g}$ was added to one sample, and the other sample served as a control. Both samples were then subdivided into 1-g portions and incubated at $10^{\circ} \mathrm{C}$ for 4 weeks. The LM content of the steak tartare was analyzed by adding $90 \mathrm{ml}$ of physiological salt solution $(154 \mathrm{mM} \mathrm{NaCl})$ to a $1-\mathrm{g}$ steak tartare sample in a stomacher bag, which was massaged for $90 \mathrm{~s}$ in a stomacher machine (Interscience, St. Nom, France). Colony counts were conducted on TSA plates onto which $100 \mu$ l of decimal sample dilutions in physiological salt solution had been plated. The whole experiment was performed in duplicate.

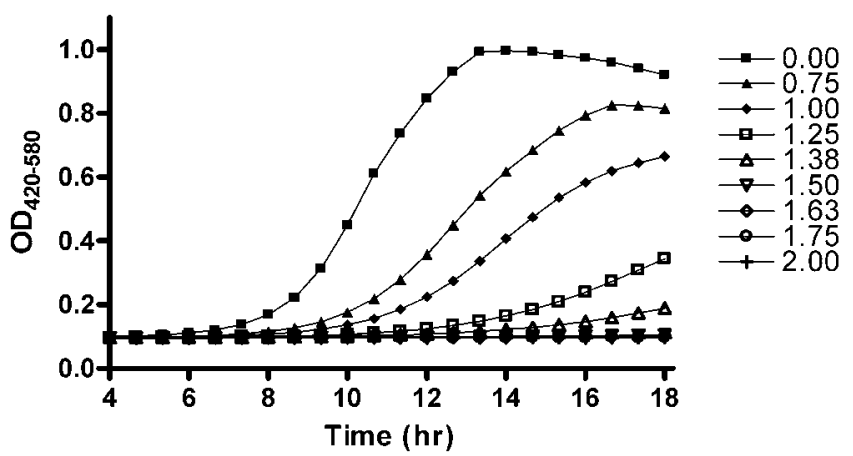

FIGURE 1. Growth curve of Listeria monocytogenes in TSB in the presence of different concentrations of carvacrol.

Inhibition of carvacrol activity by egg yolk and bovine serum albumin. The effect of egg yolk (a main component of the steak tartare sauce) and bovine serum albumin (BSA; a ground beef constituent) on the activity of carvacrol was determined. Growth of LM in TSB at $30^{\circ} \mathrm{C}$ in the presence of $2.5 \mathrm{mM}$ carvacrol and 0 to $1 \%$ (wt/vol) BSA (Sigma-Aldrich Chemie $\mathrm{GmbH}$, Steinheim, Germany) or 0 to $2 \%$ (wt/vol) egg yolk (Oxoid Ltd., Basingstoke, UK) was determined based on the increase in the $\mathrm{OD}_{420-580}$. Experiments were performed in duplicate with at least three replicates per sample.

Detection of carvacrol binding to BSA. Carvacrol (final concentration of $2.5 \mathrm{mM}$ ) was incubated with 0,1 , or $2 \%$ (wt/ vol) BSA in TSB for 15 min or with $1 \%$ (wt/vol) BSA and $20 \%$ ( $\mathrm{vol} / \mathrm{vol}$ ) ethanol. Subsequently, $6 \mathrm{ml}$ of the mixture was partially filtered through a 10-kDa-pore-size filter (centriplus YM-10, Amicon, Beverly, Mass.) by centrifugation at 3,000 $\times \mathrm{g}$ for $40 \mathrm{~min}$. After centrifugation, approximately $2 \mathrm{ml}$ of the solution was filtered, and both the filtrate and the residual were collected. The carvacrol content of the incubation mixture and of both fractions after centrifugation was determined using high-pressure liquid chromatography (HPLC). This experiment was performed in triplicate.

HPLC. Quantitative detection of carvacrol in solution was performed using HPLC essentially as previously described (4). A $50-\mu 1$ sample was injected into a Phenomenex Luna C18 column (4.6 by $150 \mathrm{~mm}$ inside diameter). Elution was performed at a flow rate of $0.8 \mathrm{ml} / \mathrm{min}$ using a mixture of water (A) and acetonitrile (B) with the following characteristics: 4 min isocratic flow with $40 \% \mathrm{~B}$, B increased to $100 \%$ from 4 to $20 \mathrm{~min}$, and column washed with $100 \%$ B for 5 min. Detection was performed at 266 $\mathrm{nm}$. Under these conditions, carvacrol eluted after $14 \mathrm{~min}$ as a single peak separated from BSA and TSB components.

Statistical analysis. Statistical analysis was performed using SPSS version 10.0.5 for Windows (SPSS, Chicago, Ill.). Data were analyzed by one-way analysis of variance followed by a Bonferroni test. Differences were considered significant at $P<$ 0.05 .

\section{RESULTS}

Determination of MIC. The MIC was determined for carvacrol against LM using a microdilution broth assay at $30^{\circ} \mathrm{C}$. Representative growth curves of one experiment are shown in Figure 1. Increasing amounts of carvacrol ( 0 to $2.0 \mathrm{mM}$ ) led to an extended lag phase, lower maximum growth rate, and lower final bacterial densities. Details of these growth curves (and curves that are not shown in Fig- 
TABLE 1. Growth curve from a microdilution assay of LM treated with carvacrol at $30^{\circ} \mathrm{C}^{a}$

\begin{tabular}{cccc}
\hline $\begin{array}{c}\text { Carvacrol } \\
\text { concn } \\
(\mathrm{mM})\end{array}$ & $\begin{array}{c}\text { Final bacterial } \\
\text { density } \\
\left(\mathrm{OD}_{420-580} \times 10\right)^{b}\end{array}$ & $\begin{array}{c}\text { Minimum } \\
\text { doubling time } \\
(\mathrm{min})^{c}\end{array}$ & $\begin{array}{c}\text { Lag phase } \\
(\mathrm{min})^{d}\end{array}$ \\
\hline 0.00 & $9.2 \pm 0.4$ & $77 \pm 1$ & 400 \\
0.75 & $8.2 \pm 0.1$ & $110 \pm 0$ & 507 \\
0.88 & $7.0 \pm 0.2$ & $127 \pm 3$ & 546 \\
1.00 & $6.5 \pm 0.1$ & $134 \pm 2$ & 560 \\
1.13 & $4.7 \pm 0.2$ & $177 \pm 7$ & 653 \\
1.25 & $3.4 \pm 0.2$ & $210 \pm 8$ & 760 \\
1.38 & $1.9 \pm 0.1$ & $309 \pm 22$ & 907 \\
1.50 & $1.1 \pm 0.0$ & $2,302 \pm 695$ & \\
1.63 & $1.0 \pm 0.1$ & & \\
1.75 & $1.0 \pm 0.0$ & & \\
1.88 & $1.0 \pm 0.0$ & & \\
2.00 & $1.0 \pm 0.0$ & & \\
\hline
\end{tabular}

$a$ Values are mean \pm standard deviation.

${ }^{b}$ The final $\mathrm{OD}_{420-580}$ after $18 \mathrm{~h}$ was multiplied by 10 for clarity.

${ }^{c}$ Minimum doubling time is indicative of the slope of the growth curve in the exponential phase of growth.

${ }^{d}$ Lag phase is defined as the time point when $\mathrm{OD}_{420-580}>0.15$.

ure 1 for clarity reasons) are given in Table 1 . Thus, 1.63 $\mathrm{mM}$ was determined to be the lowest concentration at which no growth could be detected, which is defined as the MIC.

Bactericidal effect of carvacrol in steak tartare. To limit the effect of the natural flora on growth of LM and carvacrol activity against LM, only steak tartare that contained aerobic bacteria at less than $10^{5} \mathrm{CFU} / \mathrm{g}$ was used (determined by colony counting assay). Subsequently, steak tartare was spiked with $10^{7} \mathrm{CFU} / \mathrm{g} \mathrm{LM}$, treated with 5 $\mathrm{mmol} / \mathrm{g}$ carvacrol, and incubated at $10^{\circ} \mathrm{C}$ for 4 weeks. Spiked LM could be completely recovered from the steak tartare by massaging 1-g samples in physiological salt solution (data not shown). The growth of LM in carvacroltreated steak tartare compared with the carvacrol-free control is shown in Figure 2. No difference was observed after the addition of carvacrol. Growth was detected after 2 weeks, leading to a 10-fold increase in LM after 4 weeks for both treated and control samples.

Bactericidal activity of carvacrol at different temperatures. To determine the effect of temperature on the bactericidal activity of carvacrol, LM in TSB was incubated for $96 \mathrm{~h}$ with $0,1.25$ (<MIC), and 2.5 (>MIC) $\mathrm{mM}$ carvacrol at 10,20 , and $30^{\circ} \mathrm{C}$. Colony counts were carried out to determine the number of surviving LM (Fig. 3). The highest bactericidal activity of $2.5 \mathrm{mM}$ carvacrol was observed at $30^{\circ} \mathrm{C}$, where a $4-\log$ decrease occurred after 24 h. At $20^{\circ} \mathrm{C}$, only a bacteriostatic effect was observed after $96 \mathrm{~h}$, whereas at $10^{\circ} \mathrm{C}$ only a slight reduction $(0.6 \mathrm{log})$ in the number of surviving LM was detected. At the sub-MIC concentration of $1.25 \mathrm{mM}$ carvacrol, LM growth was slower and lower final bacterial densities were found at all temperatures, although the effect was relatively small at $30^{\circ} \mathrm{C}$.

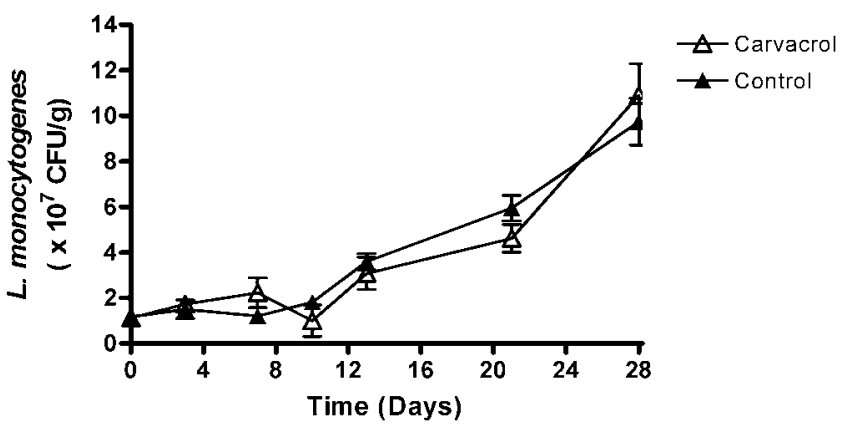

FIGURE 2. Growth of Listeria monocytogenes in steak tartare with (open triangles) and without (closed triangles) $5 \mathrm{mmol} / \mathrm{g} \mathrm{car}$ vacrol added. Bars indicate mean value \pm standard deviation.
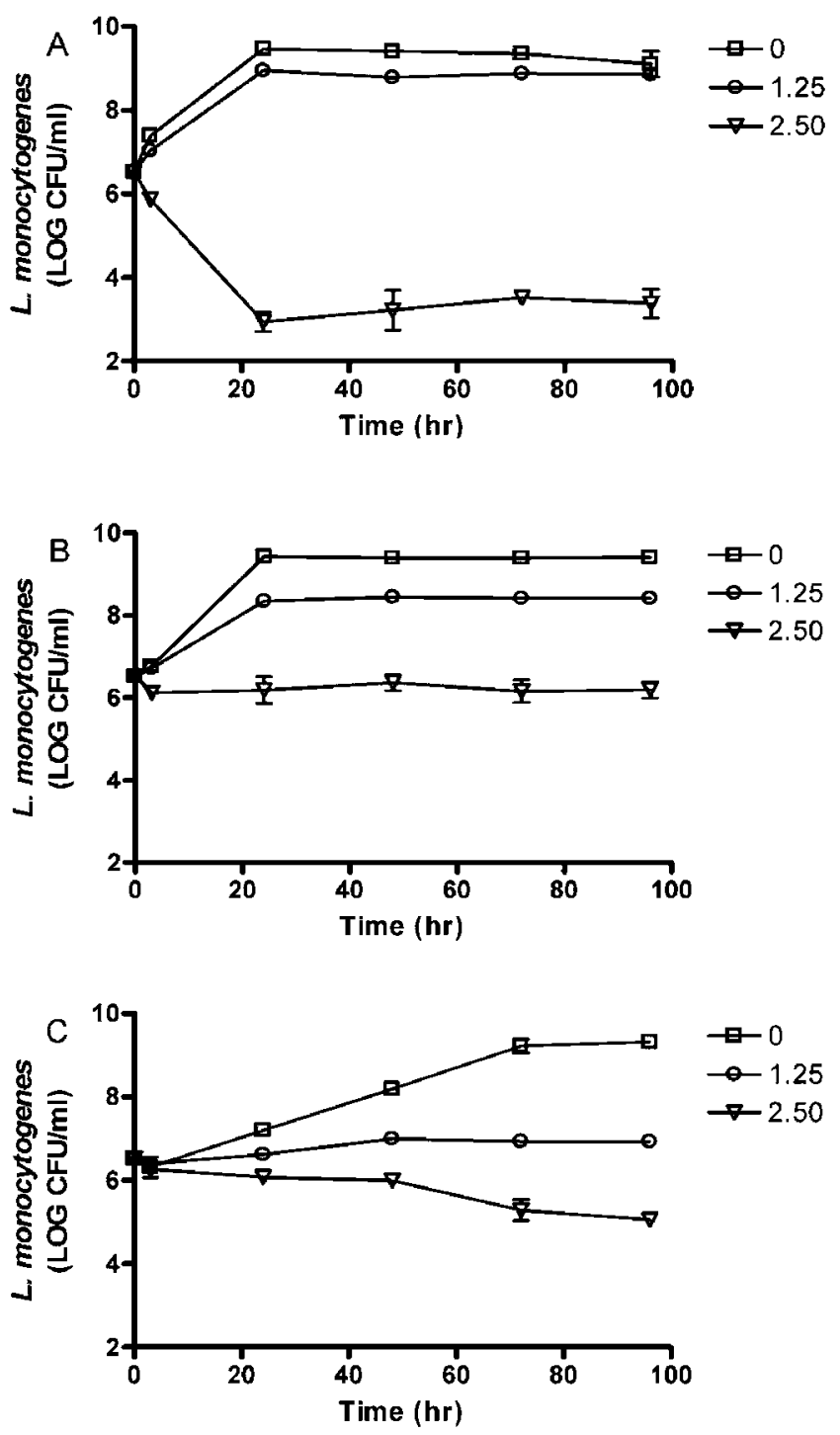

FIGURE 3. Effect of temperature on the bactericidal activity of carvacrol in TSB. Listeria monocytogenes was incubated with 0 , 1.25 (sub-MIC), and $2.5 \mathrm{mM}$ carvacrol at three temperatures: (A) $30^{\circ} \mathrm{C}$, (B) $20^{\circ} \mathrm{C}$, and $(\mathrm{C}) 10^{\circ} \mathrm{C}$. Survival of $L M$ was determined by colony counting. Values are the mean \pm standard deviation. 

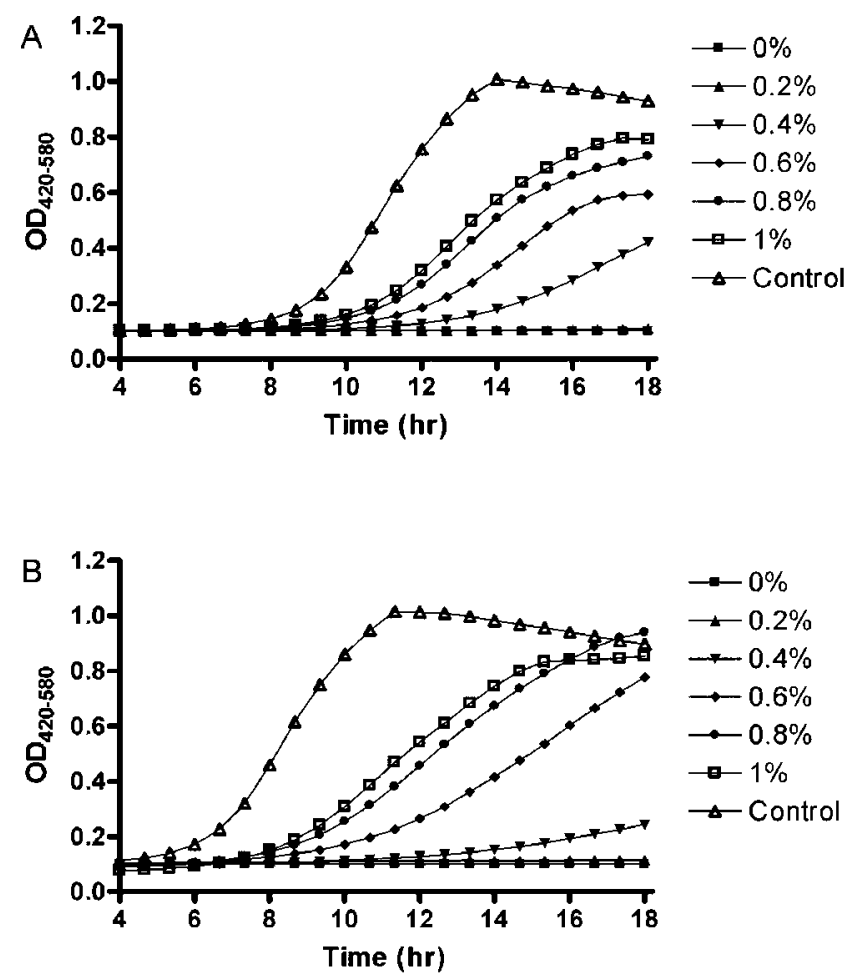

FIGURE 4. Effect of BSA (A) and egg yolk (B) on the growth inhibiting effect of carvacrol in TSB. Representative growth curves are shown for Listeria monocytogenes in the presence of $2.5 \mathrm{mM}$ carvacrol and increasing concentrations of BSA or egg yolk. Control, the growth curve of L. monocytogenes in TSB in the absence of carvacrol or BSA or egg yolk.

Inhibition of carvacrol activity. The effects of egg yolk and BSA (ingredients of the sauce and meat of the steak tartare, respectively) on the antimicrobial activity of carvacrol in TSB are shown in Figure 4. For both components separately, growth of LM occurred at a $0.4 \%(\mathrm{wt} / \mathrm{vol})$ concentration, indicative of inhibition of the activity of car- vacrol. The $0 \%$ samples, which contained $2.5 \mathrm{mM}$ carvacrol but no BSA or egg yolk, had no detectable growth after $18 \mathrm{~h}$. Higher concentrations of BSA or egg yolk led to higher final optical densities, lower maximum growth rates, and shorter lag phases (Table 2), indicative of increasing inhibition of carvacrol. However, at $1 \%$ BSA, there was some residual antimicrobial activity compared with the control (growth of LM in TSB in the absence of carvacrol). The addition of BSA or egg yolk to TSB (without carvacrol) had no effect on the growth of LM, as indicated by the similar growth rate, lag time, and minimum doubling time in these samples compared with the control (Table 2).

Binding of carvacrol to BSA. Insight into the mechanism of carvacrol inhibition by BSA was gained by applying a relatively simple binding study. Carvacrol (2.5 $\mathrm{mM}$ ) was incubated with 1 or $2 \%$ BSA for $15 \mathrm{~min}$ and

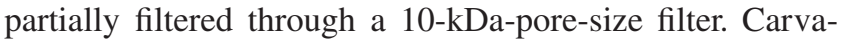
crol has a molecular mass of $150 \mathrm{Da}$ and can easily pass through the filter, whereas BSA cannot pass because of its molecular mass of $66 \mathrm{kDa}$. The interaction with BSA led to a 53\% reduction in the amount of carvacrol that passed through the filter compared with the control that contained no BSA (Fig. 5). Increasing the BSA concentration to $2 \%$ led to an even lower concentration of carvacrol $(72 \%$ reduction) in the filtrate, whereas addition of $20 \%$ ethanol (to reduce hydrophobic interactions between BSA and carvacrol) partially reversed the effect of BSA (27\% reduction in carvacrol). However, this higher carvacrol concentration in the filtrate was not significantly different from that in the $1 \%$ BSA filtrate sample without ethanol $(P=0.053)$. The higher concentration of carvacrol in the residual solution of the samples containing BSA confirmed that carvacrol was retained in the upper chamber of the centrifuge filter tube. The control sample without BSA had an equal concentration of carvacrol in both the filtrate and residual fractions, showing that carvacrol was not lost through aspecific bind-

TABLE 2. Growth curve characteristics for LM treated with $2.5 \mathrm{mM}$ carvacrol and different concentrations of BSA or egg yolk ${ }^{a}$

\begin{tabular}{|c|c|c|c|c|c|c|}
\hline \multirow[b]{2}{*}{$\begin{array}{l}\text { BSA or egg yolk } \\
(\% \mathrm{wt} / \mathrm{vol})\end{array}$} & \multicolumn{3}{|c|}{ BSA } & \multicolumn{3}{|c|}{ Egg yolk } \\
\hline & $\begin{array}{c}\text { Final bacterial } \\
\text { density } \\
\left(\mathrm{OD}_{420-580}\right)^{b}\end{array}$ & $\begin{array}{l}\text { Minimum } \\
\text { doubling time } \\
(\min )^{c}\end{array}$ & $\begin{array}{l}\text { Lag phase } \\
\quad(\min )^{d}\end{array}$ & $\begin{array}{c}\text { Final bacterial } \\
\text { density } \\
\left(\mathrm{OD}_{420-580}\right)\end{array}$ & $\begin{array}{l}\text { Minimum } \\
\text { doubling time } \\
\quad(\min )\end{array}$ & $\begin{array}{l}\text { Lag phase } \\
\text { (min) }\end{array}$ \\
\hline 0.0 & $1.0 \pm 0.0$ & & & $1.0 \pm 0.0$ & & \\
\hline 0.2 & $1.1 \pm 0.0$ & & & $1.1 \pm 0.0$ & & \\
\hline 0.4 & $2.7 \pm 0.2$ & $1,456 \pm 1,400$ & 773 & $3.3 \pm 1.1$ & $281 \pm 67$ & 740 \\
\hline 0.6 & $3.5 \pm 2.6$ & $489 \pm 391$ & 640 & $8.0 \pm 0.5$ & $168 \pm 4$ & 520 \\
\hline 0.8 & $5.8 \pm 1.7$ & $150 \pm 41$ & 687 & $9.4 \pm 0.1$ & $133 \pm 5$ & 460 \\
\hline 1.0 & $6.6 \pm 1.4$ & $131 \pm 25$ & 620 & $8.5 \pm 0.1$ & $111 \pm 8$ & 447 \\
\hline $1 \%$ BSA alone $e^{e}$ & $8.8 \pm 0.1$ & $78 \pm 2$ & 480 & & & \\
\hline $1 \%$ egg yolk alone ${ }^{e}$ & & & & $7.5 \pm 0.1$ & $74 \pm 1$ & 360 \\
\hline Controlf $^{f}$ & $9.0 \pm 0.3$ & $78 \pm 2$ & 480 & $9.1 \pm 0.5$ & $76 \pm 2$ & 320 \\
\hline
\end{tabular}

${ }^{a}$ Values are means \pm standard deviations.

${ }^{b}$ The final $\mathrm{OD}_{420-580}$ after $18 \mathrm{~h}$ was multiplied by 10 for clarity.

${ }^{c}$ Minimum doubling time is indicative of the slope of the growth curve in the exponential phase of growth.

${ }^{d}$ Lag phase is defined as the time point when $\mathrm{OD}_{420-580}>0.15$.

${ }^{e}$ Growth curve of Listeria monocytogenes in TSB without carvacrol but in the presence of $1 \%$ BSA or egg yolk.

${ }^{f}$ Growth curve of Listeria monocytogenes in TSB (without carvacrol, BSA, or egg yolk). 


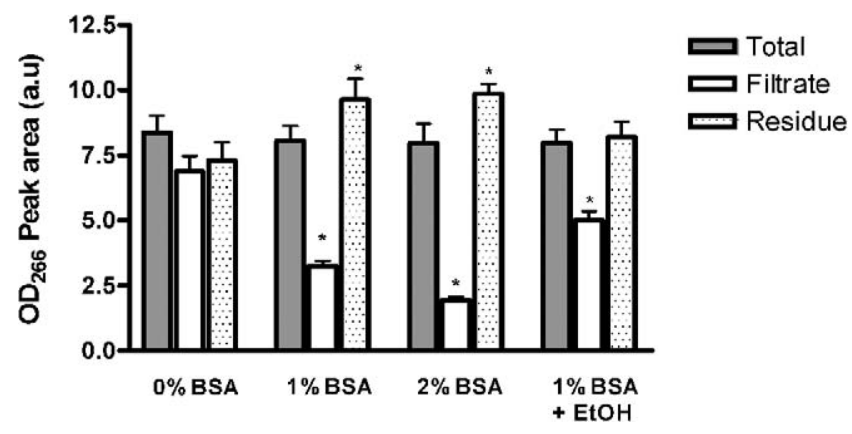

FIGURE 5. Binding of carvacrol to BSA. Carvacrol was incubated with 0, 1 (with or without 20\% ethanol), or 2\% BSA and subsequently passed through a 10-kDa-pore-size filter. Only unbound carvacrol can pass through the filter. Values are the mean \pm standard deviation.

ing to the filter. These results indicate that BSA binds to carvacrol, thereby preventing it from passing through the filter.

\section{DISCUSSION}

The antimicrobial activity of carvacrol against LM in growth medium has been described previously. The MIC determined in this study is in the same range as reported data $(21,25)$, although higher MICs $(>3 \mathrm{mM})$ also have been reported $(11,14)$. As for many other foods (3), the antilisterial activity of carvacrol in steak tartare did not match the observed activity under laboratory conditions. In steak tartare, the antibacterial activity was completely lost and LM growth was not affected by $5 \mathrm{mmole} / \mathrm{g}$ carvacrol (Fig. 2). The conditions used in this experiment did not completely replicate the real-life situation, in which steak tartare is kept at $4^{\circ} \mathrm{C}$ for maximally a few days before it is consumed. In this short time period at this temperature, no outgrowth of LM would be observed. For the experiment, incubation time and temperature were increased to allow use of steak tartare as a food matrix model to determine the effect of food components on the activity of carvacrol.

To determine the cause of the reduced activity of carvacrol, the effects of an incubation temperature lower than the $30^{\circ} \mathrm{C}$ used for the MIC determination and the inhibiting effect of some of the food matrix components were determined. At $10^{\circ} \mathrm{C}$, bactericidal activity was strongly reduced for carvacrol in TSB (Fig. 3), leading to only a small decrease in LM density at the lower temperatures. LM is known to adapt to lower temperatures by producing phospholipids with shorter and more branched fatty acids. Other factors of cold adaptation are a change in expression of membrane lipids, destabilization of ribosomes, and the uptake of osmolytes (8). Which of these factors had an effect on the bactericidal activity of carvacrol cannot be deduced from these experiments. However, the membrane is generally considered the target of carvacrol (and EOs in general) $(13,22,26)$. Therefore, the change in membrane composition seems the most logical explanation for the reduced effect of carvacrol.

The presence of proteins and fats in the food matrix is often thought to inhibit the effect of carvacrol on microbial growth $(5,9,16,17,28)$. In this experiment, we tested and identified two components of steak tartare, BSA and egg yolk, that can interfere with carvacrol activity in vitro (Fig. 4). The inhibition mechanism probably is associated with the hydrophobic nature of carvacrol, which enables BSA or egg yolk to bind to these hydrophobic components and prevent the initial interaction of carvacrol with bacteria. For BSA, this binding was observed (Fig. 5); to the best of our knowledge, this is the first time that binding of carvacrol to a protein has been described. Because egg yolk consists of a complex mixture of lipids, fatty acids, and proteins, the exact mechanism of inhibition could not be determined under our experimental conditions. We cannot conclude from our experiments that BSA or egg yolk are the main inhibiting components of steak tartare, but it seems likely that binding to food components plays an important role in the inhibition of carvacrol activity.

The observed lower activity of carvacrol in food matrices hampers its use as a food preservative. An additional problem is the aroma of carvacrol, which can interfere with the sensory characteristics of the food product. In our experiments, the aroma of carvacrol was clearly distinguishable at all concentrations used. In this respect, the use of carvacrol as a preservative might be more promising in liquid food products that do not contain many fat or protein components. In several studies, relatively good preservation has been obtained for fruit juices $(10,18,27)$, although information on the effect of the additives on sensory characteristics is often lacking. An alternative solution to the problem of the aroma might lie in the use of the hurdle strategy, where a combination of preservation techniques is used. Although each technique separately might not be sufficient to preserve the product, the combined effect could efficiently reduce microbial growth.

We tested the antilisterial activity of carvacrol in vitro and in steak tartare. Although strong antibacterial activity of carvacrol was observed in growth medium at $30^{\circ} \mathrm{C}$, no effect was seen when carvacrol was added to steak tartare at refrigeration temperatures. This lack of effect can be explained partially by lower antilisterial activity of carvacrol at these lower temperatures. The presence of certain food components also is likely an important factor. Both BSA and egg yolk strongly inhibited the antimicrobial activity of carvacrol at low concentrations. The inhibitory characteristic, at least for BSA, can be explained by direct binding of this protein to carvacrol, thereby reducing the effective concentration of carvacrol in solution.

\section{REFERENCES}

1. Arrebola, M. L., M. C. Navarro, J. Jiménez, and F. A. Ocaňa. 1994. Yield and composition of the essential oil of Thymus serpylloides subsp. serpylloides. Phytochemistry 36:67-72.

2. Aydin, S., A. A. Başaran, and N. Başaran. 2005. Modulating effects of thyme and its major ingredients on oxidative DNA damage in human lymphocytes. J. Agric. Food Chem. 53:1299-1305.

3. Burt, S. 2004. Essential oils: their antibacterial properties and potential applications in foods-a review. Int. J. Food Microbiol. 94: 223-253.

4. Burt, S. A., R. Vlielander, H. P. Haagsman, and E. J. A. Veldhuizen. 2005. Increase in activity of essential oil components carvacrol and thymol against Escherichia coli $\mathrm{O} 157: \mathrm{H} 7$ by addition of food stabilizers. J. Food Prot. 68:919-926. 
5. Canillac, N., and A. Mourey. 2004. Effects of several environmental factors on the anti-Listeria monocytogenes activity of an essential oil of Picea excelsa. Int. J. Food Microbiol. 92:95-103.

6. Chami, N., S. Bennis, F. Chami, A. Aboussekhra, and A. Remmal. 2005. Study of anticandidal activity of carvacrol and eugenol in vitro and in vivo. Oral Microbiol. Immunol. 20:106-111.

7. Cutter, C. N. 2000. Antimicrobial effect of herb extracts against Escherichia coli O157: H7, Listeria monocytogenes, and Salmonella Typhimurium associated with beef. J. Food Prot. 63:601-607.

8. Farber, J. M., and P. I. Peterkin. 1991. Listeria monocytogenes, a food-borne pathogen. Microbiol. Rev. 55:476-511.

9. Farbood, M. I., J. H. Macneil, and K. Ostovar. 1976. Effect of rosemary spice extractive on growth of microorganisms in meats. J. Milk Food Technol. 39:675-679.

10. Friedman, M., P. R. Henika, C. E. Levin, and R. E. Mandrell. 2004. Antibacterial activities of plant essential oils and their components against Escherichia coli O157:H7 and Salmonella enterica in apple juice. J. Agric. Food Chem. 52:6042-6048.

11. Friedman, M., P. R. Henika, and R. E. Mandrell. 2002. Bactericidal activities of plant essential oils and some of their isolated constituents against Campylobacter jejuni, Escherichia coli, Listeria monocytogenes, and Salmonella enterica. J. Food Prot. 65:1545-1560.

12. Gill, A. O., P. Delaquis, P. Russo, and R. A. Holley. 2002. Evaluation of antilisterial action of cilantro oil on vacuum packed ham. Int. J. Food Microbiol. 73:83-92.

13. Gill, A. O., and R. A. Holley. 2004. Mechanisms of bactericidal action of cinnamaldehyde against Listeria monocytogenes and of eugenol against L. monocytogenes and Lactobacillus sakei. Appl. Environ. Microbiol. 70:5750-5755.

14. Gill, A. O., and R. A. Holley. 2006. Disruption of Escherichia coli, Listeria monocytogenes and Lactobacillus sakei cellular membranes by plant oil aromatics. Int. J. Food Microbiol. 108:1-9.

15. Hao, Y. Y., R. E. Brackett, and M. P. Doyle. 1998. Efficacy of plant extracts in inhibiting Aeromonas hydrophila and Listeria monocytogenes in refrigerated cooked poultry. Food Microbiol. 15:367-378.

16. Ismaiel, A. A., and M. D. Pierson. 1990. Effect of sodium nitrite and Origanum oil on growth and toxin production of Clostridium botulinum in TYG broth and ground pork. J. Food Prot. 53:958960.

17. Juven, B. J., J. Kanner, F. Schved, and H. Weisslowicz. 1994. Factors that interact with the antibacterial action of thyme essential oil and its active constituents. J. Appl. Bacteriol. 76:626-631.

18. Kiskó, G., and S. Roller. 2005. Carvacrol and p-cymene inactivate Escherichia coli $\mathrm{O} 157: \mathrm{H} 7$ in apple juice. BMC Microbiol. 5:36.

19. Lindberg, C. M., A. P. Melathopoulos, and M. L. Winston. 2000. Laboratory evaluation of miticides to control Varroa jacobsoni (Acari: Varroidae), a honeybee (Hymenoptera: Apidae) parasite. J. Econ. Entomol. 93:189-198.

20. Mejlholm, O., and P. Dalgaard. 2002. Antimicrobial effect of essential oils on the seafood spoilage micro-organism Photobacterium phosphoreum in liquid media and fish products. Lett. Appl. Microbiol. 34:27-31.

21. Olasupo, N. A., D. J. Fitzgerald, A. Narbad, and M. J. Gasson. 2004. Inhibition of Bacillus subtilis and Listeria innocua by nisin in combination with some naturally occurring organic compounds. J. Food Prot. 67:596-600.

22. Oussalah, M., S. Caillet, and M. Lacroix. 2006. Mechanism of action of Spanish oregano, Chinese cinnamon, and savory essential oils against cell membranes and walls of Escherichia coli $0157: \mathrm{H} 7$ and Listeria monocytogenes. J. Food Prot. 69:1046-1055.

23. Pandit, V. A., and L. A. Shelef. 1993. Sensitivity of Listeria monocytogenes to rosemary (Rosmarinus officinalis L.). Food Microbiol. 11:57-63.

24. Panella, N. A., M. C. Dolan, J. J. Karchesy, Y. Xiong, J. PeraltaCruz, M. Khasawneh, J. A. Montenieri, and G. O. Maupin. 2005. Use of novel compounds for pest control: insecticidal and acaricidal activity of essential oil components from heartwood of Alaska yellow cedar. J. Med. Entomol. 42:352-358.

25. Pol, I. E., and E. J. Smid. 1999. Combined action of nisin and carvacrol on Bacillus cereus and Listeria monocytogenes. Lett. Appl. Microbiol. 29:166-170.

26. Rasooli, I., M. B. Rezaei, and A. Allameh. 2006. Ultrastructural studies on antimicrobial efficacy of thyme essential oils on Listeria monocytogenes. Int. J. Infect. Dis. 10:236-241.

27. Raybaudi-Massilia, R. M., J. Mosqueda-Melgar, and O. Martín-Belloso. 2006. Antimicrobial activity of essential oils on Salmonella Enteritidis, Escherichia coli, and Listeria innocua in fruit juices. J. Food Prot. 69:1579-1586.

28. Shelef, L. A., E. K. Jyothi, and M. A. Bulgarelli. 1984. Growth of enteropathogenic and spoilage bacteria in sage-containing broth and foods. J. Food Sci. 49:737-740.

29. Sökmen, M., J. Serkedjieva, D. Daferera, M. Gulluce, M. Polissiou, B. Tepe, H. A. Akpulat, F. Sahin, and A. Sökmen. 2004. In vitro antioxidant, antimicrobial, and antiviral activities of the essential oil and various extracts from herbal parts and callus cultures of Origanum acutidens. J. Agric. Food Chem. 52:3309-3312.

30. Tampieri, M. P., R. Galuppi, F. Macchioni, M. S. Carelle, L. Falcioni, P. L. Cioni, and I. Morelli. 2005. The inhibition of Candida albicans by selected essential oils and their major components. Mycopathologia 159:339-345.

31. Ultee, A., and E. J. Smid. 2001. Influence of carvacrol on growth and toxin production by Bacillus cereus. Int. J. Food Microbiol. 64: 373-378.

32. Veldhuizen, E. J. A., J. L. Tjeerdsma-van Bokhoven, C. Zweijtzer, S. A. Burt, and H. P. Haagsman. 2006. Structural requirements for the antimicrobial activity of carvacrol. J. Agric. Food Chem. 54: 1874-1879.

33. Vrinda Menon, K., and S. R. Garg. 2001. Inhibitory effect of clove oil on Listeria monocytogenes in meat and cheese. Food Microbiol. 18:647-650. 